Journal of Advanced Research in Fluid Mechanics and Thermal Sciences

Journal homepage: www.akademiabaru.com/arfmts.html ISSN: 2289-7879

\title{
Experimental Investigation on a Desiccant Silica Bed for Dehumidification
}

\author{
Pravinth Balthazar ${ }^{1,2}$, Mohd Azmi Ismail ${ }^{1,}{ }^{*}$, Mohammad Nazmi Mohammad Nasir $^{1}$, Hussin Mamat ${ }^{3}$, \\ Muhammad Iftishah Ramdan ${ }^{1}$
}



\section{ARTICLE INFO}

Article history:

Received 25 January 2020

Received in revised form 1 May 2020

Accepted 9 May 2020

Available online 31 July 2020

\section{Keywords:}

Silica gel; solid desiccant;

dehumidification; adsorption; hollow

cylinder

\section{ABSTRACT}

Energy demand is getting higher from time to time all over the world especially in Malaysia. In order to cope with energy cost and climate change that taking place to achieve the thermal comfort, alternative cooling methods should be placed to reduce consumption of energy. Desiccant cooling technique is one of the promising alternative method, avoids the refrigerants use and eliminate effect on the ozone layer. This study focused on single layer hollow silica gel bed dehumidification ability as the solid desiccant material under variable air velocity between $1 \mathrm{~ms}^{-1}$ to $5 \mathrm{~ms}^{-1}$. Experimental investigation concluded that moisture adsorption ability is increased respect to air velocity for hollow desiccant arrangement for $1 \mathrm{~ms}^{-1}$ to $2.1 \mathrm{~ms}^{-1}$ range. However, 2.1 $\mathrm{ms}^{-1}$ to $5 \mathrm{~ms}^{-1}$ showed steep decrease in moisture adsorption. $5 \mathrm{~ms}^{-1}$ air velocity illustrated 10.5 times lower dehumidification than $3.7 \mathrm{~ms}^{-1}$.

Copyright @ 2020 PENERBIT AKADEMIA BARU - All rights reserved

\section{Introduction}

Climate change and energy cost are the phenomena that transforming the global marketing into new era. Building industries in Malaysia are consuming most of the energy in commercial buildings [1-3]. Fifth assessment report from the Intergovernmental Panel on Climate Change (IPCC) reported that, from 1983 to 2012 was the warmest global land and ocean for the past 800 years [4]. Nowadays, the air conditioning systems are playing a vital role by consuming around $60 \%$ total energy in buildings and releasing higher Global Warming Potential (GWP) valued refrigerant to atmosphere. Therefore, it is an urging problem to choose an alternative method to optimize the efficiency of air conditioning systems by reducing the energy consumption and eliminate the production of higher GWP refrigerants.

\footnotetext{
* Corresponding author.

E-mail address: azmi_meche@usm.my
}

https://doi.org/10.37934/arfmts.73.2.111 
The combination of desiccant dehumidification and air conditioning system (Hybrid system) have gained attention in recent past as the substitute to the conventional air-conditioning system. Moisture in air can be dehumidified by direct contact between humid air and dry desiccant material than over cooling in evaporator. Desiccant material can be regenerated by using low grade regeneration heat source such as solar thermal energy [5-8] or waste heat from a cogeneration of other sources [9]. Maclaine-Cross is the first to propose hybrid air conditioning system in 1988 [10]. His proposal consists of a heat exchanger, heating coils and fans, a regenerative dehumidifier and an evaporative cooler to handle latent load and part of sensible load and remaining sensible load will be handled by a gas engine driven chiller. However, compatibility and commercially available effective model to replace with conventional systems were proposed after the invention of desiccant wheels [11].

A wide range of materials were used in desiccant air-conditioning systems. Activated alumina, zeolite and silica gel are few that can be used to desorb using solar energy or waste heat because of its regeneration ability at low temperature [12]. Silica gel is a one of the fine solid desiccant material can adsorb up to $40 \%$ of its dry weight in water. As it in equilibrium with air at saturation, it can withstand temperatures up to $400{ }^{\circ} \mathrm{C}$ and insoluble desiccant. In addition, it is static, stable, nontoxic, and resistant to most chemicals and no special safety measures are required when it is exposed to air at $100 \%$ relative humidity. Silica gel undergo no physical and chemical change during the adsorption process [13].

According to comparison study by Dupont et al., [14], they concluded that the alumina performs $30 \%$ less water per unit dry mass than silica gel. Then, Kim et al., [15] was conducted an experimental study on low pressure drop desiccant bed for solar air conditioning applications by using silica gel under laminar flow. In 2002, Hamed [16] used burned clay to study the adsorption characteristics of vertical packed porous bed by on transient flow. After that, Hamed et al., [17] extended his study on the transient adsorption characteristics of solid desiccant in a vertical fluidized bed. In 2008 Kabeel [18] expanded Hamed et al., [16,17] researches in adsorption operations of multilayer desiccant packed bed for dehumidification. The packed bed had eight equal layers. All the studies mentioned above were conducted in axial air flow. As a consequence, Awad et al., [19] have performed an analysis on radial flow using silica gel. Their theoretical and experimental study used hollow cylindrical bed and concluded that $\mathbf{7 . 2}$ diameter ratio hollow cylindrical bed showed the highest efficient operation compared to the other four test samples.

The objective of the present experimental study is to investigate the effect of the single layer hollow cylindrical packed bed performance for adsorption process under axial flow. The experimental tests were carried out at different operating conditions including air velocity, relative humidity and temperature, in order to evaluate the performance of desiccant material.

\section{Methodology}

HVAC experimental rig that available in School of Mechanical Engineering, Universiti Sains Malaysia has been modified in order to investigate desiccant dehumidification performance. The HVAC experimental rig consists of cooling coil, axial fan, heater, humidifier compartment and testing section as illustrated in Figure 1. The hollow cylindrical desiccant bed is positioned at the testing section to observe the effect of air velocity with respect to dehumidification.

Hollow cylindrical desiccant bed was used to study the dehumidification ability of the silica gel as solid desiccant adsorbent. The silica gel have average grain diameter between 3 and $4 \mathrm{~mm}$. Single layer desiccant hollow cylindrical bed was fabricated to study the ability of the adsorption of the silica gel under axial flow conditions. The total surface area of the silica gel bed for the systems is 213.63 
$\mathrm{cm}^{2}$. The length of the dehumidifier system is $30 \mathrm{~cm}$ as shown in Figure 2. Outer diameter of experimental silica bed is $10.5 \mathrm{~cm}$ and inner diameter is $6.5 \mathrm{~cm}$. Total weight of dry Silica gel used in experiment is $5 \mathrm{~kg}$.

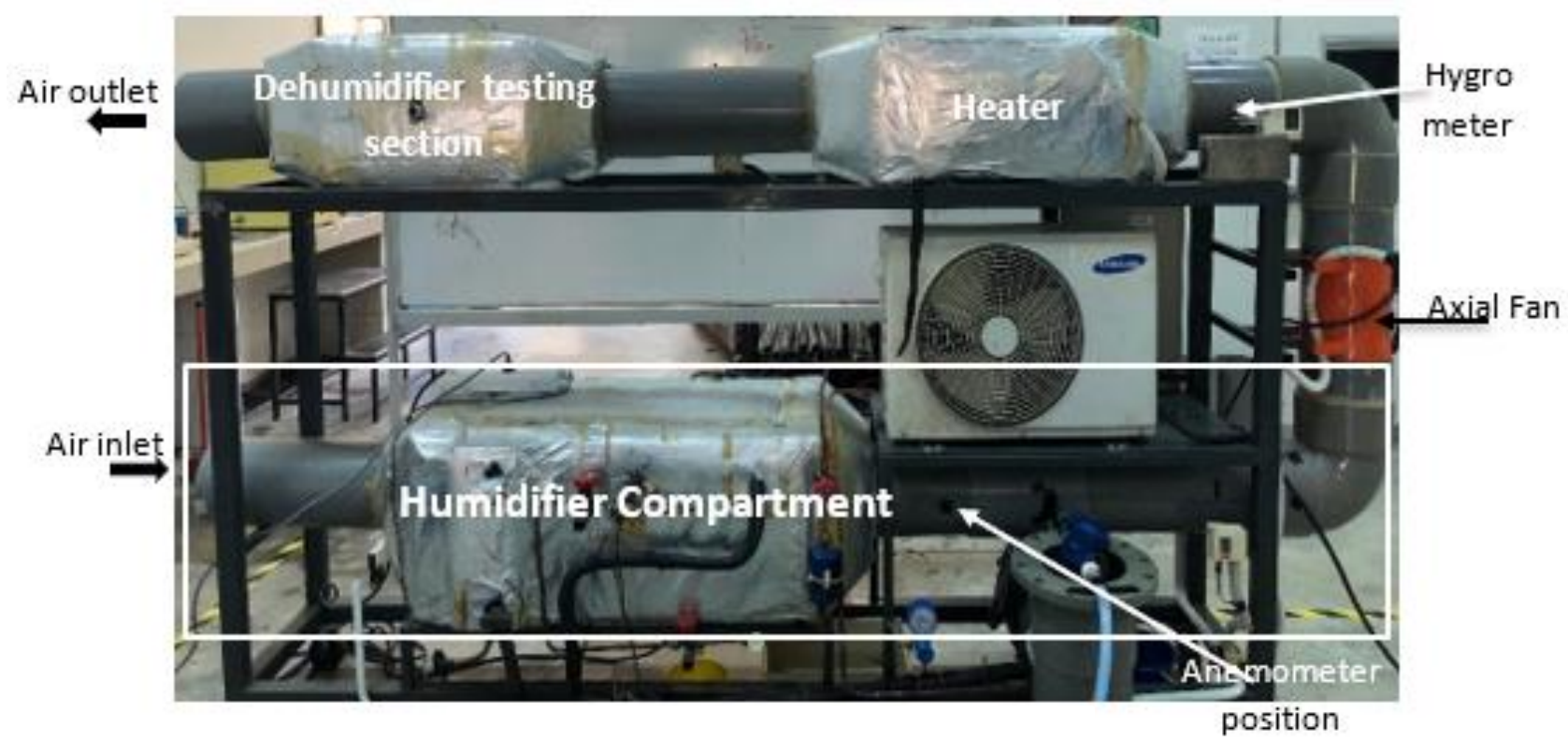

Fig. 1. Desiccant experimental unit

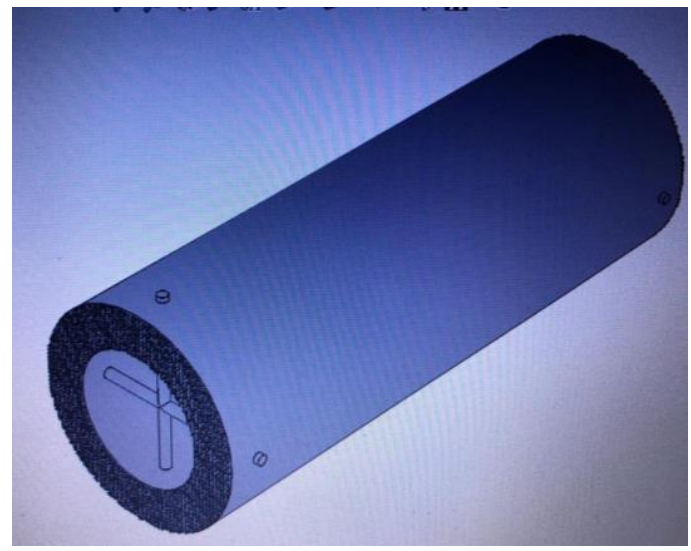

Fig. 2. Desiccant Hollow cylindrical bed

In present work, the water mist spray was included into the experimental unit to control inlet relative humidity $(\mathrm{RH})$ with respect to air velocity. The flow meter and hygrometer are used to measure the velocity of the air, and relative humidity and the temperature, respectively. The desiccant bed was installed inside the test section. As illustrated in Figure 3, the dry bulb and wet bulb thermocouples used to measure temperature downstream of desiccant or test section. The reading of $\mathrm{RH}$, dry and wet bulb temperatures at both air inlet and outlet taken for every 10 second interval using data loggers. Humidified air supplied throughout the dehumidifier system for around two hours.

Later on, the desiccant bed was dried by heated air (temperature at $90^{\circ} \mathrm{C}$ ) flow pass through it around two hours before the adsorption process begin for next air velocity. This precaution taken to ensure that any moisture contained in the silica gel inside the test bed are removed and maintained as bench mark for throughout all the air velocities between $1 \mathrm{~ms}^{-1}$ and $5 \mathrm{~ms}^{-1}$. All adsorption 
experiment was carried out during morning between $8.30 \mathrm{am}$ to $12.00 \mathrm{pm}$ in order to reduce the uncertainty in atmospheric conditions.

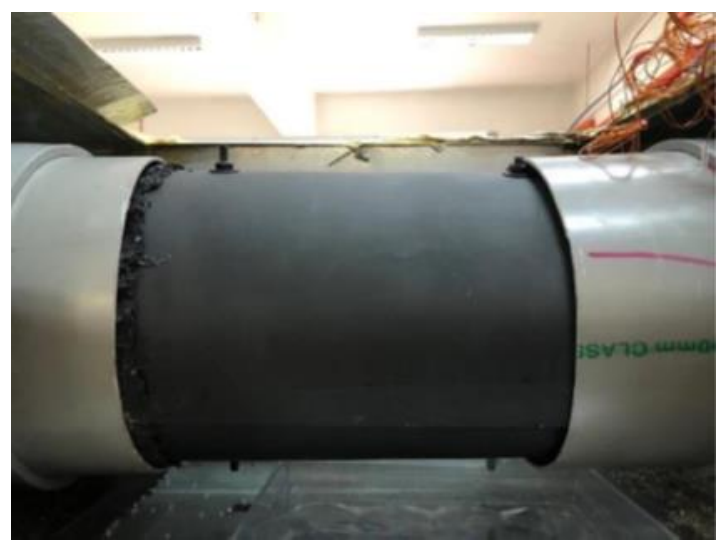

(a)

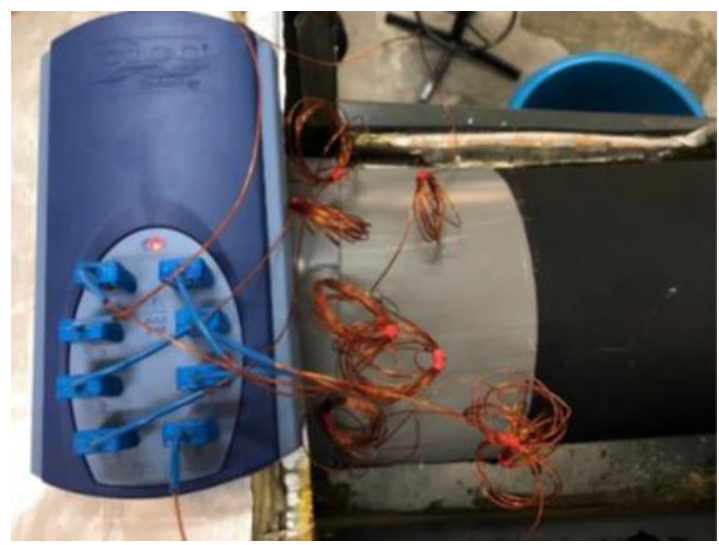

(b)

Fig. 3. (a) Experimental setup desiccant bed (b) Thermocouple arrangement

\section{Results}

\subsection{The Observation of Dry Bulb and Wet Bulb Temperatures at the Desiccant Bed Outlet}

The performance of hollow cylinder desiccant silica packed bed during adsorption processes was evaluated by carrying out series of experiments under different inlet conditions and air velocities. The outlet dry bulb and wet bulb temperature readings, inlet dry bulb temperature and inlet relative humidity from the experiments were recorded against time. Outlet relative humidity, inlet and outlet humidity ratio, total moisture absorption and adsorption humidity ratio were calculated using psychometric chart and plotted respect to time.

Figure 4 illustrates the observation of all the dry and wet bulb temperature reading at downstream of hollow cylindrical desiccant bed for air velocity of $1.5 \mathrm{~ms}^{-1}$. There were four dry bulb (Channel 1, 3, 5 and 7) and wet bulb thermocouples (Channel 2, 4, 6, and 8) positioned $90^{\circ}$ apart to each other as a set. All the dry bulb and wet bulb thermocouples reading were taken into account and average dry and wet bulb temperatures used for the calculation. Similarly, all the observational temperature readings were taken for experiments at $1 \mathrm{~ms}^{-1}, 1.5 \mathrm{~ms}^{-1}, 2.1 \mathrm{~ms}^{-1}$ and $3.7 \mathrm{~ms}^{-1}$ velocities. 


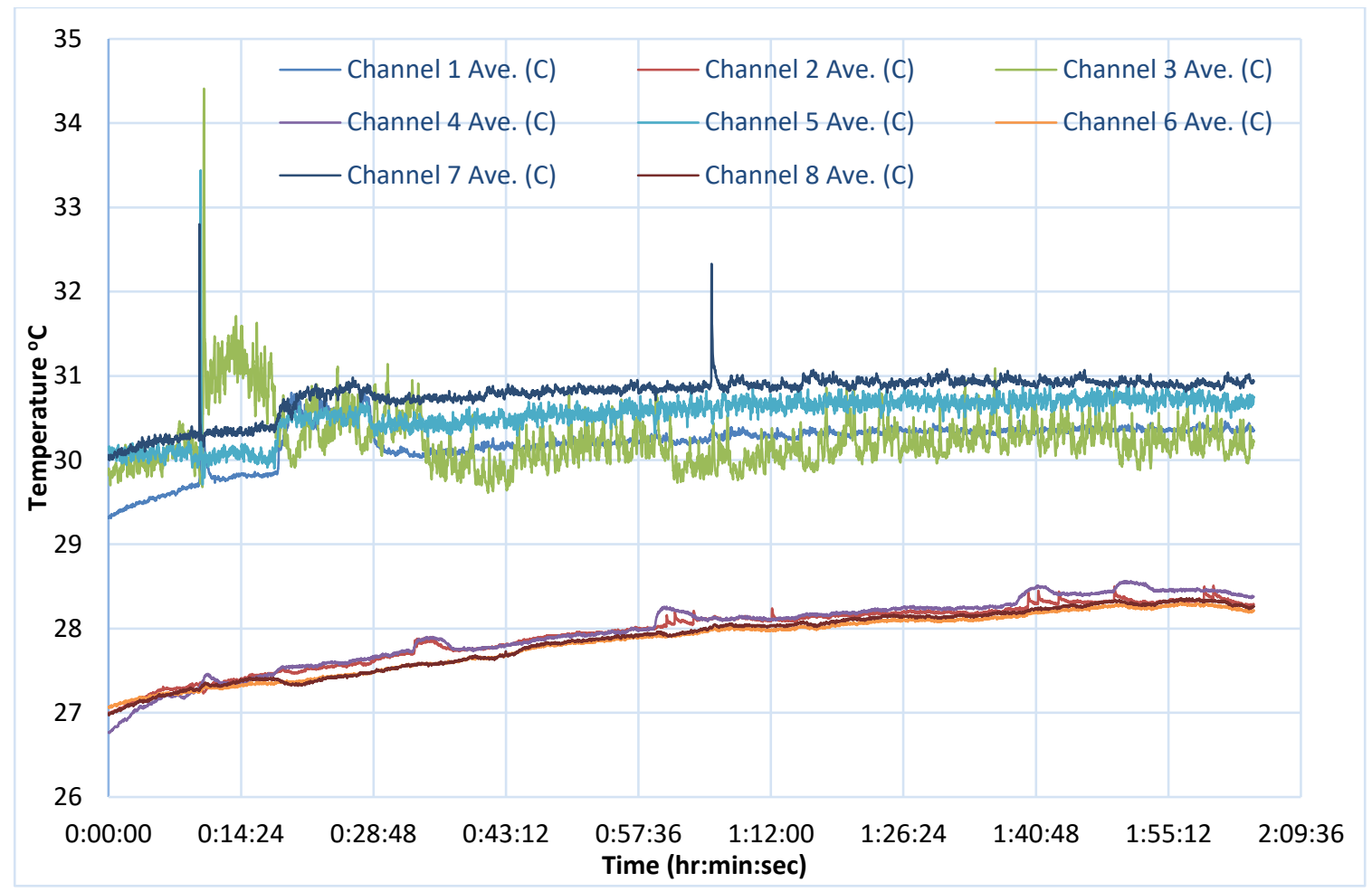

Fig. 4. Experimental data for $1.5 \mathrm{~ms}^{-1}$ air velocity

\subsection{The Relative Humidity (RH) and Temperature Variation Respect to Inlet and Outlet Air}

Figure 5(a), 6(a) and 5(b), 6(b) demonstrate inlet and outlet $\mathrm{RH}$ and temperature values respectively for $1 \mathrm{~ms}^{-1}$ and $3.7 \mathrm{~ms}^{-1}$ air velocity. Specifically, for Figure 5(a) and 6(a), Silica desiccant material adsorbing moisture in the air almost similar in both cases like 10 to $12 \%$ at the start of the process. After 30 minutes, $1 \mathrm{~ms}^{-1}$ velocity showed steady relative humidity absorption comparing to $3.7 \mathrm{~ms}^{-1}$ air velocity. End of 90 minutes of experiment $1 \mathrm{~ms}^{-1}$ showed $50 \%$ higher relative humidity reduction rate compared to $3.7 \mathrm{~ms}^{-1}$. This figures observation might be a key to control the air flow through the desiccant material to control the exit relative humidity under required conditions.

Figure $5(b)$ and $6(b)$ describe that inlet temperature always less then outlet temperature. This phenomenon happen due to any desiccant material adsorb the moisture, it will release the thermal energy to the atmosphere.

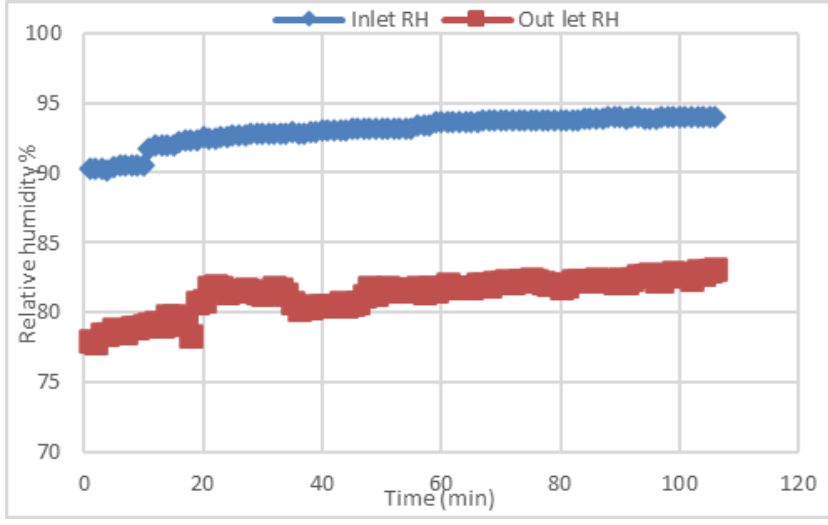

(a)

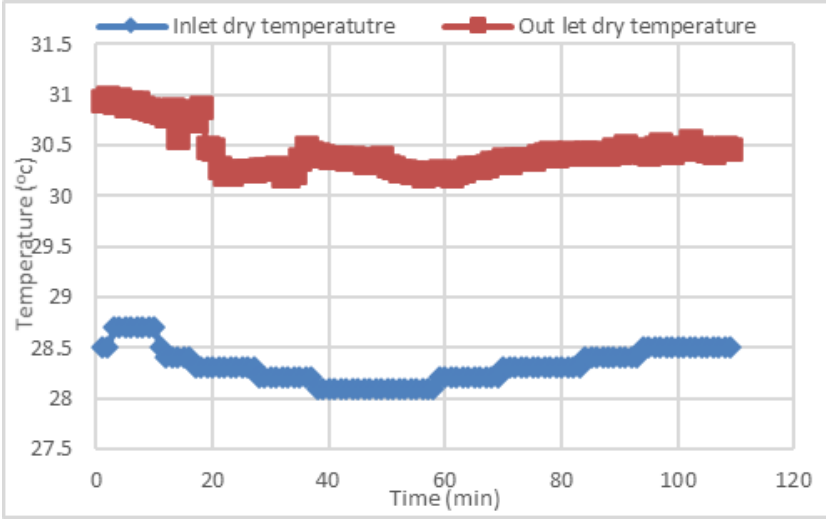

(b)

Fig. 5. (a) RH for $1 \mathrm{~ms}^{-1}$ (b) Temperature variation for $1 \mathrm{~ms}^{-1}$ 


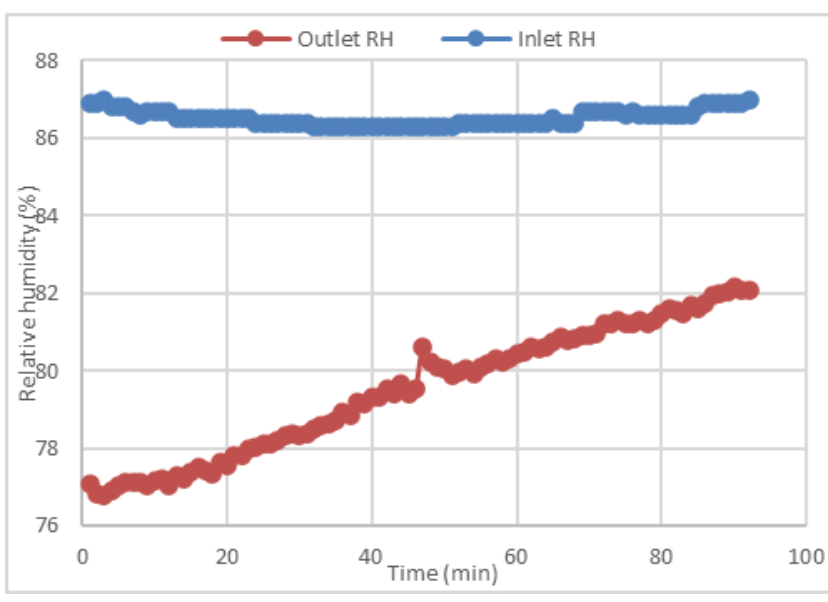

(a)

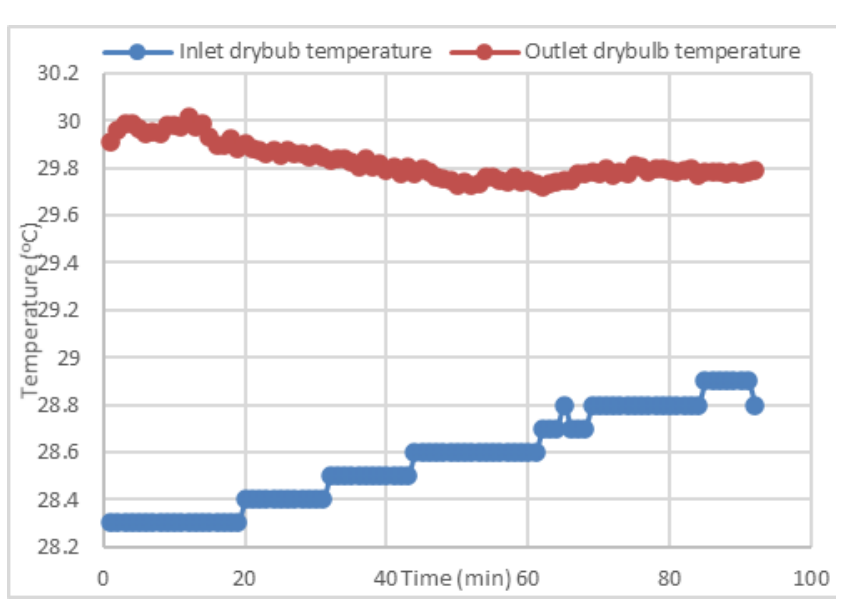

(b)

Fig. 6. (a) RH for $3.7 \mathrm{~ms}^{-1}$ (b) Temperature variation for $3.7 \mathrm{~ms}^{-1}$

\subsection{The Effect of Inlet and Outlet Air Humidity Ratio Distribution}

Figure 7 and Figure 8 illustrate the variation of humidity of the inlet and exit air from the packed bed with time during the adsorption process. The humidity ratio difference between inlet and outlet depends on the time and the velocity as shown from the figures, as it hard to reach steady state condition. The difference between the humidity ratio of exit and inlet air almost $1.2 \mathrm{~g} / \mathrm{kg}$ at the start of the adsorption process for $1 \mathrm{~ms}^{-1}$ and $1.26 \mathrm{~g} / \mathrm{kg}$ for $3.7 \mathrm{~ms}^{-1}$ air velocities. However, after 60 minutes, air velocity at $1 \mathrm{~ms}^{-1}$ showed $0.9 \mathrm{~g} / \mathrm{kg}$ humidity ratio difference and on the other hand, and air velocity at $3.7 \mathrm{~ms}^{-1}$ showed $0.52 \mathrm{~g} / \mathrm{kg}$ humidity ratio difference. Even though air velocity at $1 \mathrm{~ms}^{-1}$ showed $28.4 \%$ higher humidity ratio adsorption by 40 minutes time comparing to air velocity at 3.7 $\mathrm{ms}^{-1}$ velocity, air velocity of $3.7 \mathrm{~ms}^{-1}$ have $62.3 \%$ higher total water mist adsorption rate than that of $1 \mathrm{~ms}^{-1}$, as shown in Figure 9. A potential reason of above mentioned phenomenon is the higher flow rate of the air stream throughout the process. Air velocity at $1 \mathrm{~ms}^{-1}$ never reached to it silica desiccants' fully adsorbed condition within the 120 min experiment. However, at air velocity at 3.7 $\mathrm{ms}^{-1}$, it took $93 \mathrm{~min}$ to achieve fully adsorbed region. This trend conclude that total moisture adsorption is proportional to air velocities for $1 \mathrm{~ms}^{-1}$ and $3.7 \mathrm{~ms}^{-1}$ by only comparing two graph.

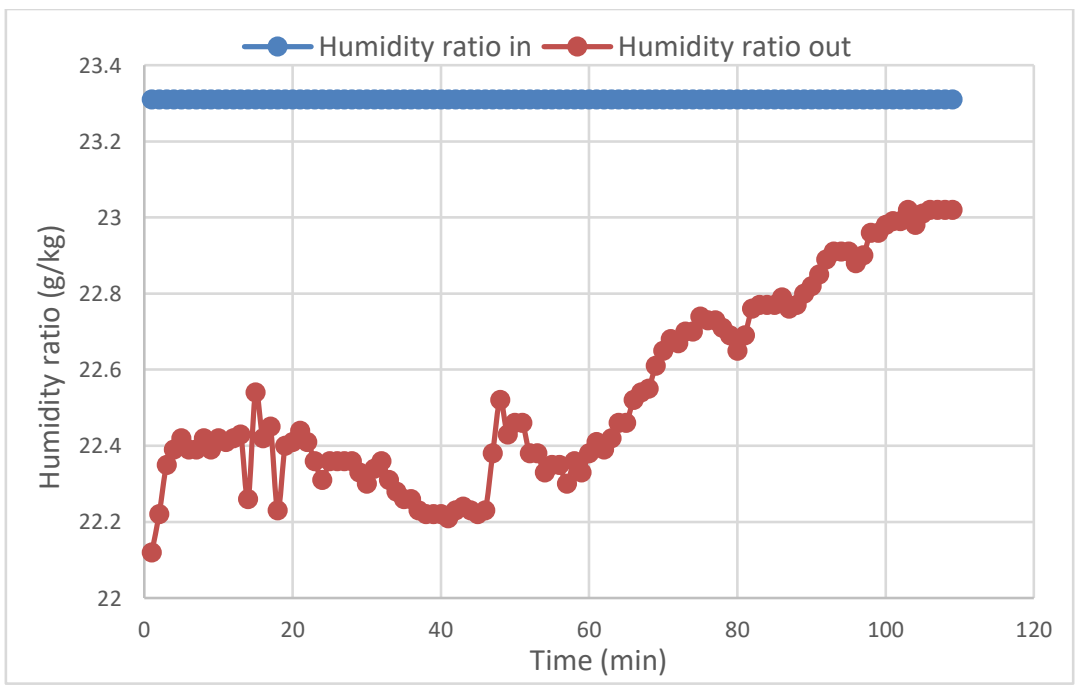

Fig. 7. Humidity ratio at inlet and outlet for $1 \mathrm{~ms}^{-1}$ 


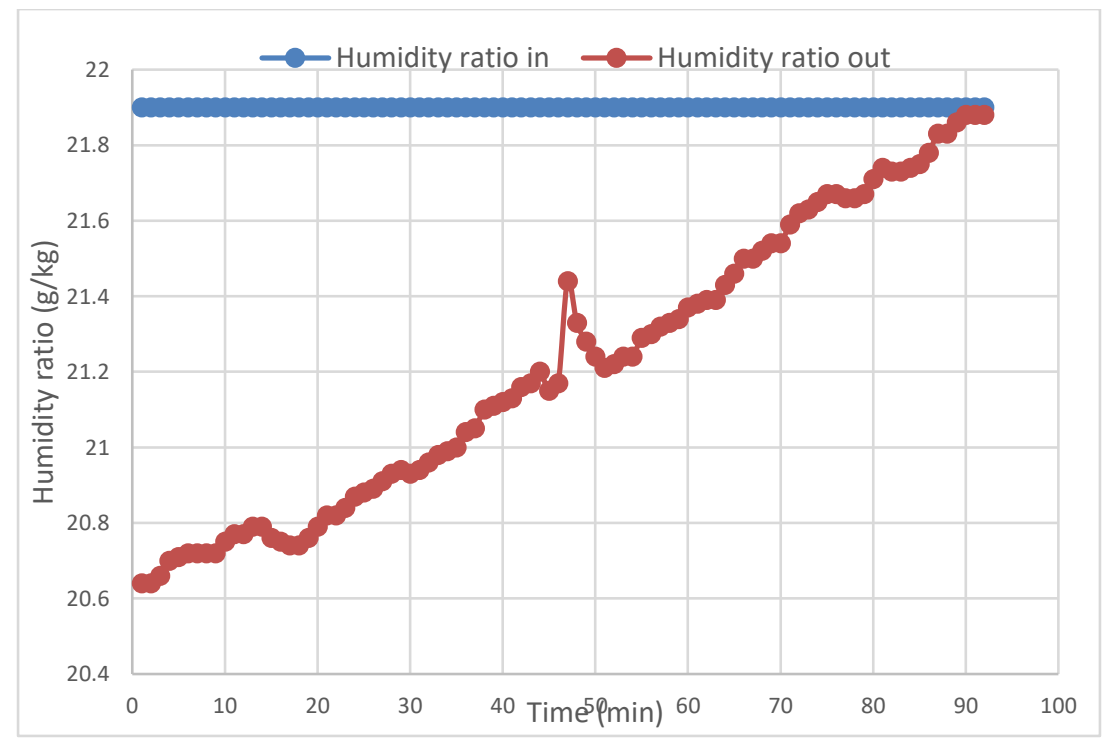

Fig. 8. Humidity ratio at inlet and outlet for $3.7 \mathrm{~ms}^{-1}$

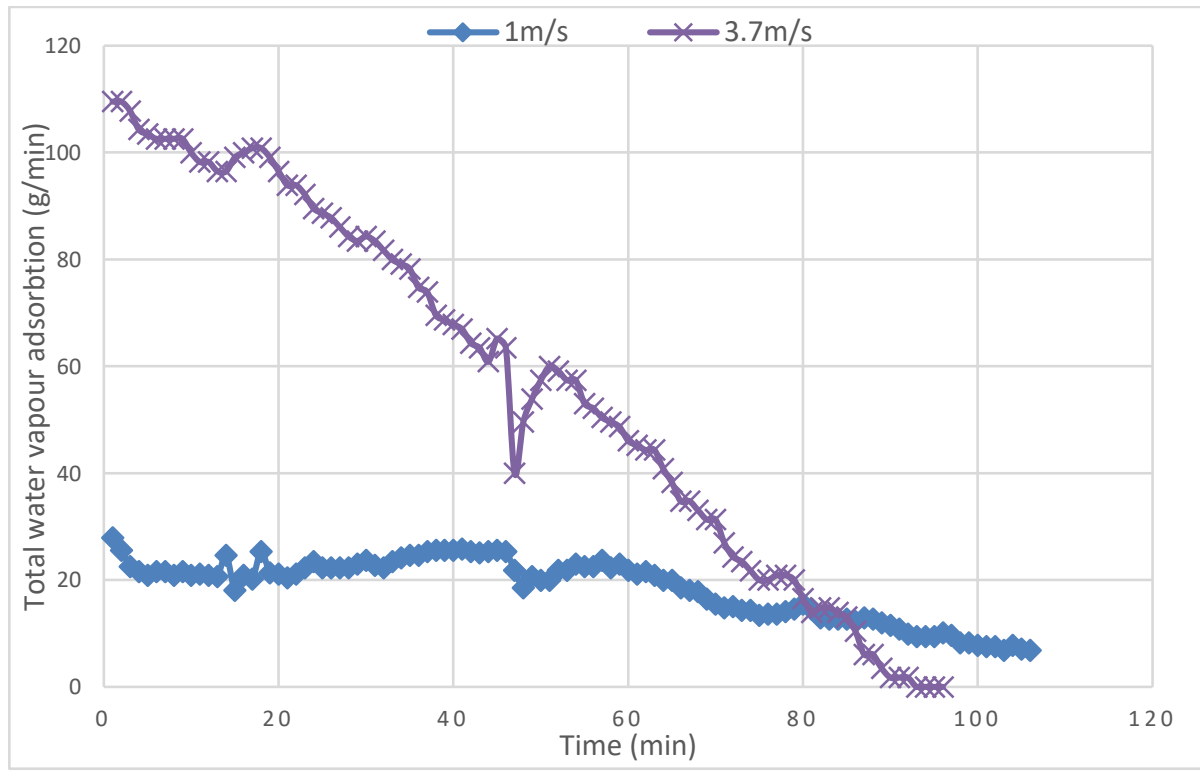

Fig. 9. Total water vapour adsorption for $1 \mathrm{~ms}^{-1}$ and $3.7 \mathrm{~ms}^{-1}$

\subsection{The Effect of Hollow Cylindrical Bed to Adsorption Humidity Ratio and Air Velocity}

The Figure 10 illustrate the phenomena with humidity adsorption under various air velocities. However, each velocities have different inlet conditions to begin with as the experiments were done in different days. Desiccant silica gel not saturated under air velocities at $1 \mathrm{~ms}^{-1}$ and $1.5 \mathrm{~ms}^{-1}$ during 120 min experiment. Air velocities at $2.1 \mathrm{~ms}^{-1}$ and $3.7 \mathrm{~ms}^{-1}$ saturated the desiccant bed at 109 and 93 min duration, respectively. 


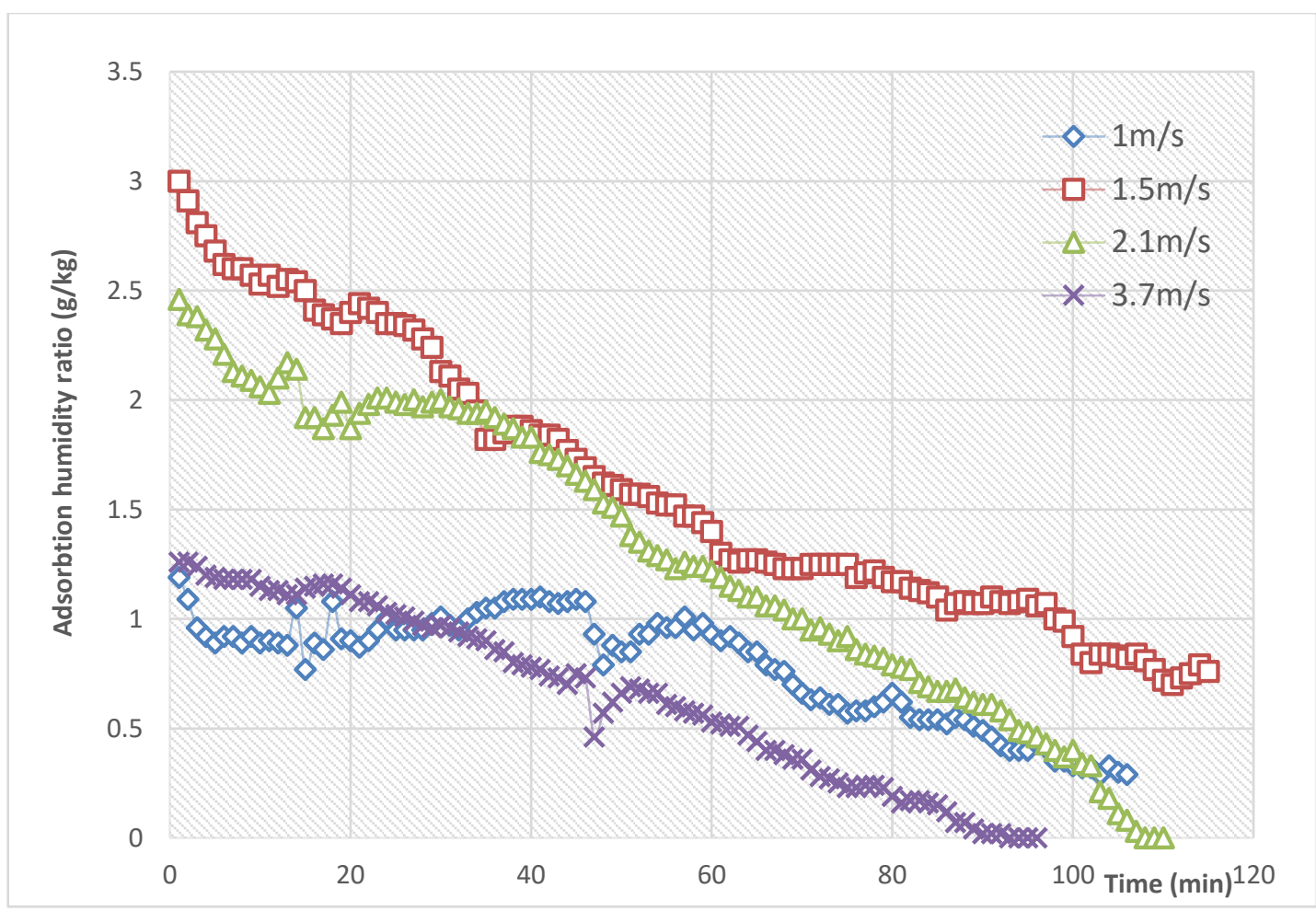

Fig. 10. Adsorption Humidity ratio under different air velocity

Figure 11 explains the average water vapour adsorption respect to air velocity throughout the experiment carried out duration. At air velocity of $1.5 \mathrm{~ms}^{-1}$, it showed $200 \%$ higher average adsorption rate than that of $1 \mathrm{~ms}^{-1}$ velocity. The air velocity at $2.1 \mathrm{~ms}^{-1}$ showed $18.5 \%$ higher average vapour adsorption than that of $1.5 \mathrm{~ms}^{-1}$ air velocity. However, air velocity $3.7 \mathrm{~ms}^{-1}$ showed $9.4 \%$ lower average vapour adsorption comparing to air velocity at $2.1 \mathrm{~ms}^{-1}$. A potential reason behind this unexpected trend is the hollow cylindrical shape of the experimental unit. This geometrical shape is complex to get a definite conclusion. The hollow cylinder have two parts, one is solid silica desiccant (porous material) and another hollow part with vacant gap. Desiccant bed produces pressure drop and hollow part not affect any pressure drop for air to moving through.

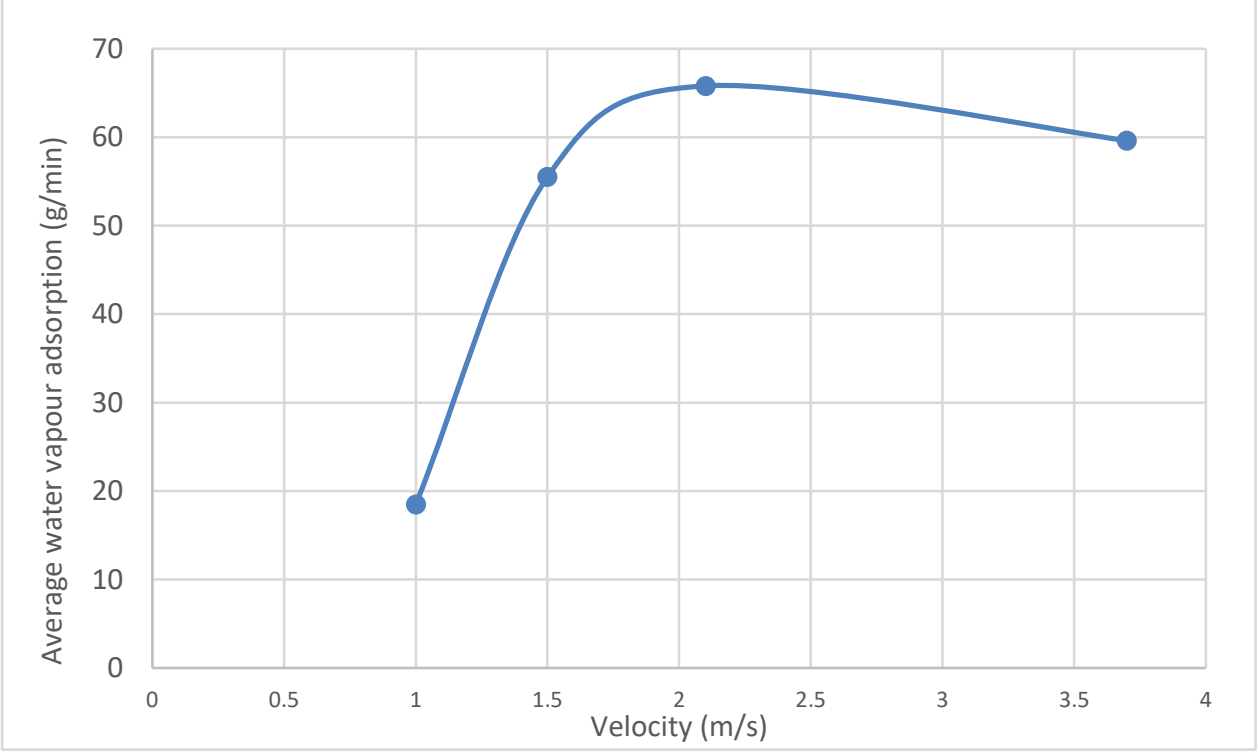

Fig. 11. Rate of adsorption respect to air velocity 
Hollow cylindrical bed adsorption can be dived into two separate adsorption area, as shown in the Figure 12. First is inner radius surface (Area 1) and second is typical desiccant adsorption (Area 2). Air stream is flowing through both solid desiccant and hollow bed, and the theory of air separation phenomenon over solid body is possibly occur at the inlet of the cylindrical bed. As a result, the low velocity air stream has low turbulent disturbance. It's not affecting the moisture transfer between air and silica gel while moving through solid desiccant. On the other hand, the higher the velocity produces higher the turbulence in air flow, subsequently it reduces the quantity of air flow through the desiccant material and causes the drop in the average water vapour adsorption. To verify this hypothesis another experiment was conducted for $5 \mathrm{~ms}^{-1}$ air velocity.
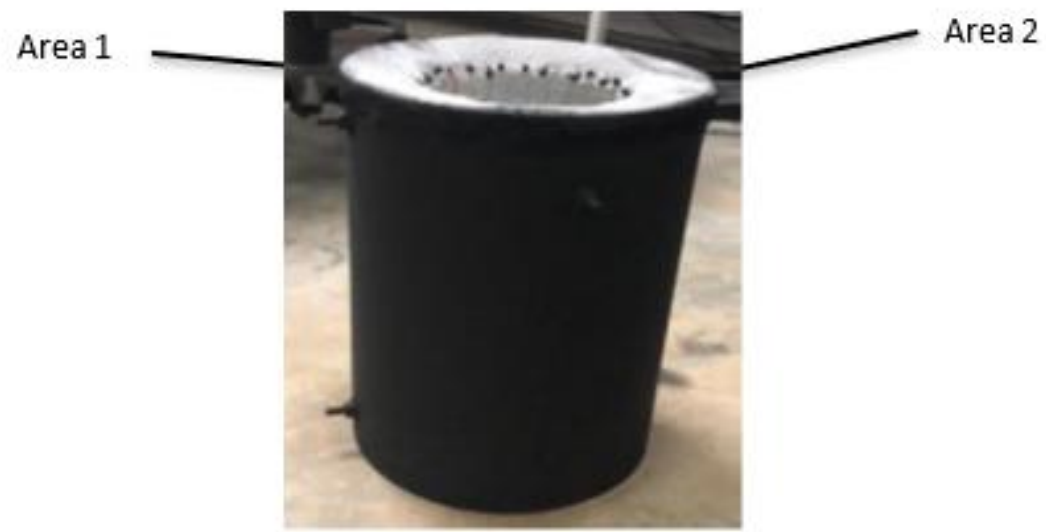

Fig. 12. Separation of hollow desiccant bed adsorption area

\subsection{The Effect of Hollow Cylindrical Bed Absorption at $5 \mathrm{~ms}^{-1}$ Air Velocity}

Figure 13 illustrates the total humidity adsorption at $5 \mathrm{~ms}^{-1}$ air velocity. Desiccant silica gel got saturated at 15 minutes which is six time faster than $3.7 \mathrm{~ms}^{-1}$ air velocity. The only possible reason for this phenomena is $5 \mathrm{~ms}^{-1}$ air velocity causes the highest turbulence than any other air velocities with respective Reynolds number 57620 . It reduces air mass flow rate through the desiccant bed and majority of air mass flow rate flows through the inner diameter surface part of the desiccant bed. This affected total average water adsorption which is $37.3 \mathrm{~g} / \mathrm{min}$ by value and $37.4 \%$ lower than 3.7 $\mathrm{ms}^{-1}$.

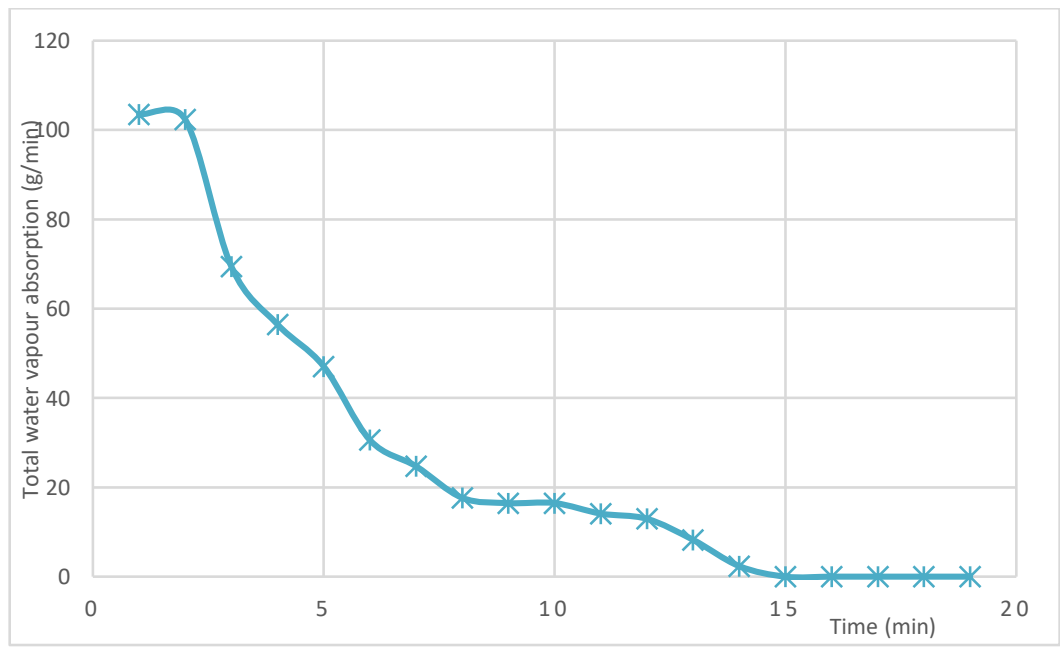

Fig. 13. Total Humidity adsorption at $5 \mathrm{~ms}^{-1}$ air velocity 


\section{Conclusions}

The present work recorded experimental data and summarized that

i. Humidity ratio, water vapour adsorption decreased and exit relative humidity increased with the time and throughout the all the air velocities.

ii. Desiccant material Silica gel not saturated for air velocities $1 \mathrm{~ms}^{-1}$ and $1.5 \mathrm{~ms}^{-1}$ within experimental duration.

iii. Air velocity $2.1 \mathrm{~ms}^{-1}$ showed $18.5 \%$ higher average adsorption rate than $1.5 \mathrm{~ms}^{-1}$.

iv. Water vapour adsorption increased from $1 \mathrm{~ms}^{-1}$ to $2.1 \mathrm{~ms}^{-1}$ after that it showed steep decrease until $5 \mathrm{~ms}^{-1}$ air velocity.

v. Air velocity $5 \mathrm{~ms}^{-1}$ showed $43.3 \%$ lower average adsorption rate than $2.1 \mathrm{~ms}^{-1}$ and lowest total moisture adsorption throughout the study.

\section{Acknowledgement}

This research was funded by Universiti Sains Malaysia, grant code 304/PMEKANIK/6315150 and South Eastern University of Sri Lanka, grant code UGC/VC/DRIC/PG2017 (II)/SEUSL/01

\section{References}

[1] Awang, Norati Artini, Haslinda Mohamed Kamar, and Nazri Kamsah. "Energy saving potential of an air-conditionerice thermal storage (AC-ITS) system." Journal of Advanced Research in Fluid Mechanics and Thermal Sciences 31, no. 1 (2017): 1-10.

[2] Balthazar, Pravinth, Mohd Azmi Ismail, A. S. B. A. Soberi, Muhammad Iftishah Ramdan, and Hussin Mamat. "Experimental Study of the Effect of Piccolo Tube Pipe on the Air-Conditioning Experimental Rig." Journal of Advanced Research in Fluid Mechanics and Thermal Sciences 53, no. 1 (2019): 95-105.

[3] Kahlib, Nor Amyra Zulianey, Farah Diana Mohd Daud, Maizirwan Mel, and Ahmad Zahirani Ahmad. "Synthesis and characterization of silica ceramic membranes via sol-dip coating." Journal of Advanced Research in Materials Science 39, no. 1 (2017): 1-7.

https://doi.org/10.30967/ijcrset.1.S1.2018.378-383

[4] Tang, Kuok Ho Daniel. "Climate change in Malaysia: Trends, contributors, impacts, mitigation and adaptations." Science of the Total Environment 650 (2019): 1858-1871.

https://doi.org/10.1016/i.scitotenv.2018.09.316

[5] Angrisani, Giovanni, Alfonso Capozzoli, Francesco Minichiello, Carlo Roselli, and Maurizio Sasso. "Desiccant wheel regenerated by thermal energy from a microcogenerator: experimental assessment of the performances." Applied Energy 88, no. 4 (2011): 1354-1365.

https://doi.org/10.1016/i.apenergy.2010.09.025

[6] Calise, F., M. Dentice d'Accadia, C. Roselli, M. Sasso, and F. Tariello. "Desiccant-based AHU interacting with a CPVT collector: Simulation of energy and environmental performance." Solar energy 103 (2014): 574-594.

https://doi.org/10.1016/i.solener.2013.11.001

[7] Wang, Xinli, Wenjian Cai, Jiangang Lu, Youxian Sun, and Xudong Ding. "A hybrid dehumidifier model for real-time performance monitoring, control and optimization in liquid desiccant dehumidification system." Applied energy 111 (2013): 449-455.

https://doi.org/10.1016/j.apenergy.2013.05.026

[8] Qi, Ronghui, Lin Lu, Hongxing Yang, and Fei Qin. "Investigation on wetted area and film thickness for falling film liquid desiccant regeneration system." Applied energy 112 (2013): 93-101.

https://doi.org/10.1016/i.apenergy.2013.05.083

[9] Angrisani, Giovanni, Carlo Roselli, Maurizio Sasso, and Francesco Tariello. "Dynamic performance assessment of a micro-trigeneration system with a desiccant-based air handling unit in Southern Italy climatic conditions." Energy conversion and management 80 (2014): 188-201.

https://doi.org/10.1016/i.enconman.2014.01.028

[10] Maclaine-Cross, I. L. "Proposal for a hybrid desiccant air-conditioning system." ASHRAE transactions 94 (1988): 1997-2009. 
[11] Eicker, Ursula, Uwe Schürger, Max Köhler, Tianshu Ge, Yanjun Dai, Hui Li, and Ruzhu Wang. "Experimental investigations on desiccant wheels." Applied Thermal Engineering 42 (2012): 71-80. https://doi.org/10.1016/j.applthermaleng.2012.03.005

[12] Development of solar desiccant humidifier. Technical progress report, No. 87-14957-1. Research Manufacturing Company of California; 1978.

[13] Munters Cargocaire Engineering Corp. Dehumidification for all requirements. Munters Cargocaire Engineering Corp. USA, 2001.

[14] Dupont, M., B. Celestine, P. H. Nguyen, J. Merigoux, and B. Brandon. "Desiccant solar air conditioning in tropical climates: I-Dynamic experimental and numerical studies of silicagel and activated alumina." Solar Energy 52, no. 6 (1994): 509-517. https://doi.org/10.1016/0038-092X(94)90658-0

[15] Kim, S., P. Biswas, and A. F. Mills. "A Compact Low-Pressure Drop Desiccant Bed for Solar Air Conditioning Applications-2: Bench Scale Tests." (1985): 120-127. https://doi.org/10.1115/1.3267664

[16] Hamed, Ahmed M. "Theoretical and experimental study on the transient adsorption characteristics of a vertical packed porous bed." Renewable Energy 27, no. 4 (2002): 525-541. https://doi.org/10.1016/S0960-1481(01)00112-4

[17] Hamed AM, Walaa R, El-Emam SH. "Study of the transient adsorption/ desorption characteristics of solid desiccant particles in fluidized bed." In The third Minia international conference for advanced trends in engineering, Minia University, Egypt; 2005.

[18] Kabeel, A. E. "Adsorption-desorption operations of multilayer desiccant packed bed for dehumidification applications." Renewable Energy 34, no. 1 (2009): 255-265. https://doi.org/10.1016/i.renene.2008.04.011

[19] Awad, M. M., A. M. Hamed, and M. M. Bekheit. "Theoretical and experimental investigation on the radial flow desiccant dehumidification bed." Applied Thermal Engineering 28, no. 1 (2008): 75-85.

https://doi.org/10.1016/i.applthermaleng.2006.12.018 